\author{
Wiesław GĄDEK ${ }^{1}$ \\ Włodzimierz BANACH ${ }^{2}$ \\ Robert SZCZEPANEK ${ }^{3}$
}

\title{
HYDROLOGICZNY MODEL WISTOO - REAKTYWACJA
}

\begin{abstract}
Model transformacji opadu w odpływ WISTOO został opracowany w 1996 r. w Zakładzie Hydrologii Instytutu Inżynierii i Gospodarki Wodnej Politechniki Krakowskiej przy współudziale Politechniki Warszawskiej. Został on stworzony na zamówienie Ministerstwa Ochrony Środowiska, Zasobów Naturalnych i Leśnictwa, finansowany ze środków Narodowego Funduszu Ochrony Środowiska i Gospodarki Wodnej. Model WISTOO, czyli Wizualizacja Integralnego Systemu Transformacji Opadu w Odpływ, jest jedynym modelem w kraju określanym jako model integralny o parametrach rozłożonych, który może być stosowany dla zlewni o powierzchni od 10 do $1000 \mathrm{~km}^{2}$. Parametry do modelu wyznaczane są automatycznie na podstawie czterech warstw tematycznych: NMT (Numerycznego Modelu Terenu), sieci hydrograficznej, kategorii pokrycia terenu oraz kategorii gleb. Warstwy tematyczne są przetwarzane do formatu IDRISI. Zapotrzebowanie na obliczenia hydrologiczne prowadzone przy użyciu modeli hydrologicznych o parametrach rozłożonych wzrosło w ostatnim okresie, lecz największym ograniczeniem jest nadal przygotowanie aktualnych warstw tematycznych. Wychodząc naprzeciw takiemu zapotrzebowaniu rozpoczęto prace nad wykorzystaniem w modelu WISTOO danych pochodzących z usług sieciowych (WMS, WFS, WCS). W artykule omówiono zalety oraz wady takiego rozwiązania.
\end{abstract}

Słowa kluczowe: spływ powierzchniowy, spływ podpowierzchniowy, procesy hydrologiczne, WMS, WFS, WCS

\section{Wstęp}

Opracowany blisko dwadzieścia lat temu w Zakładzie Hydrologii Instytutu Inżynierii i Gospodarki Wodnej Politechniki Krakowskiej przy współudziale Politechniki Warszawskiej model WISTOO jest nadal w naszym kraju jedynym modelem integralnym o parametrach rozłożonych [12].

${ }^{1}$ Autor do korespondencji/ corresponding author: Wiesław Gądek, Politechnika Krakowska, ul. Warszawska 24, 30-155 Kraków, tel. 1262828 54, wieslaw.gadek@iigw.pk.edu.pl

2 Włodzimierz Banach, Państwowa Wyższa Szkoła Wschodnioeuropejska w Przemyślu, ul. Żołnierzy 1 Armii Wojska Polskiego 1E, 37-700 Przemyśl, tel. 1673552 54, wbanach@ @wsw.pl

${ }^{3}$ Robert Szczepanek, Instytut Inżynierii i Gospodarki Wodnej Politechniki Krakowskiej, ul. Warszawska 24, 30-155 Kraków, tel. 1237420 80, robert.szczepanek@iigw.pk.edu.pl 
Został on opracowany na zamówienie Ministerstwa Ochrony Środowiska, Zasobów Naturalnych i Leśnictwa, finansowany ze środków Narodowego Funduszu Ochrony Środowiska i Gospodarki Wodnej.

Model WISTOO, czyli Wizualizacja Integralnego Systemu Transformacji Opadu w Odpływ, był zastosowany w szeregu prac naukowych dotyczących problematyki powodziowej dla zlewni: Soły, Bystrzycy Dusznickiej, Trzebuńki, Wielkiej Puszczy, Isepnicy oraz na obszarze Francji dla rzeki I'Yzeron [2, 3, 4, $5,7,11,14]$.

W okresie w którym powstawał model WISTOO, zagadnienia związane z Systemami Informacji Geograficznej (GIS) były na etapie dynamicznego rozwoju, lecz bez wyraźnie dominujących standardów. Uznano, że najbardziej odpowiadającym wymogom tworzonego modelu będzie format opracowany przez Clark Labs w Clark University [1] dla potrzeb program IDRISI.

Obecnie można zauważyć zwiększone zainteresowanie modelowaniem hydrologicznym. Stosowane są głównie modele hydrologiczne o parametrach skupionych, zaś do wyznaczania opadu efektywnego często wykorzystuje się metodę SCS CN [6, 13, 15].

Tego typu podejście ma szereg zalet, związanych głównie z dużą szybkością obliczeń i łatwością przygotowania danych wejściowych do modelu. Wadą jest to, że wyniki są obarczone błędami wynikającymi z przybliżonego sposobu wyznaczania opadu efektywnego oraz prowadzenia obliczeń transformacji opadu w odpływ w odniesieniu do środka ciężkości zlewni.

Błędy te są częściowo eliminowane przez założenie, że obliczenia prowadzone są dla małych zlewni.

W praktyce jednak modele takie są stosowane dla większych zlewni, przekraczając granice stosowalności modeli o parametrach skupionych. Problem ten rozwiązywany jest poprzez zastosowane modeli o parametrach częściowo rozłożonych z dodatkowym zastosowaniem modeli hydrologicznych transformacji w korytach cieków.

Wspomniane powyżej czynniki spowodowały, że zaistniały sprzyjające warunki przywrócenia do szerszego stosowania modelu WISTOO. Model ten może spełniać rolę niezależnego weryfikatora dla modeli o parametrach skupionych lub częściowo rozłożonych, lub też do prowadzenia niezależnych obliczeń symulacyjnych.

\section{Opis struktury modelu}

W modelu WISTOO można wyróżnić dwie części:

- wstępną obróbkę i przygotowanie danych, w tym wyznaczanie wartości parametrów dla poszczególnych modeli cząstkowych i ustalenie hierarchii obliczeniowej rastrów,

- właściwe obliczenia transformacji opadu w odpływ. 
W ramach części dotyczącej obróbki i przygotowania danych wykorzystywane są procedury:

- przygotowania numerycznego modelu terenu (NMT),

- estymacji parametrów dla zadanego przestrzennego rozkładu gleb i pokrycia terenu z uwzględnieniem zagospodarowania,

Struktura modelu zakłada: a) Jest to integralny model hydrologiczny o parametrach rozłożonych, bez podziału obszaru na zlewnie kontrolowane i niekontrolowane.

b) Uwzględniane są istotne procesy wpływające na symulowaną transformację opadu w odpływ, a w szczególności: intercepcja, ewapotranspiracja, infiltracja, spływ powierzchniowy i podpowierzchniowy, odpływ gruntowy i całkowity.

c) Do opisu poszczególnych procesów zastosowano modele hydrodynamiczne.

d) Model zawiera wbudowany moduł estymacji parametrów, umożliwiający automatyczne przyporząakkowanie parametrów modeli cząstkowych odpowiedzialnych za symulację poszczególnych procesów hydrologicznych. Parametry wyznaczane są na podstawie przestrzennej informacji o rozmieszczeniu gleb i zagospodarowaniu terenu.

e) Model został opracowany w środowisku Systemów Informacji Geograficznej dla systemu operacyjnego Windows.

f) Przyjętym elementem obliczeniowym jest raster, którego wymiary boku mogą wynosić od 10 do $100 \mathrm{~m}$. Dla każdego takiego elementu wykonywane są obliczenia wszystkich wymienionych $\mathrm{w}$ punkcie b) procesów hydrologicznych.

g) Żaden z wymiarów rastrowej warstwy obliczeniowej nie może przekroczyć 2000 elementów. Jest to maksymalna liczba wierszy i kolumn.

\subsection{Procedury przygotowania danych wejściowych}

Procedura estymacji parametrów wyznacza na potrzeby obliczeniowe modelu WISTOO parametry dla poszczególnych procesów hydrologicznych.

Programy te podzielono w zależności od cyfrowych warstw tematycznych:

- estymacja parametrów pokrycia,

- estymacja parametrów topograficznych,

- estymacja parametrów infiltracyjnych.

$\mathrm{Na}$ podstawie informacji pozyskanych $\mathrm{z}$ czterech wymienionych warstw, wyznaczane są w sposób automatyczny (niezależny od użytkownika) następujące wielkości: hierarchia zasilania, wektor zasilania, współrzędne x i y, nachylenie (spadek terenu i cieku), moduł prędkości dla fali kinematycznej, wysokość retencji pokrycia, wysokości pokrycia, współczynnik rozdziału opadu w modelu intercepcji, maksymalna przewodność hydrauliczna gruntu, porowatość gruntu. 
a

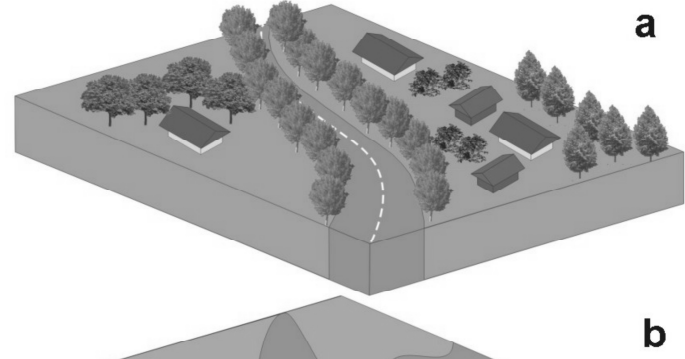

b
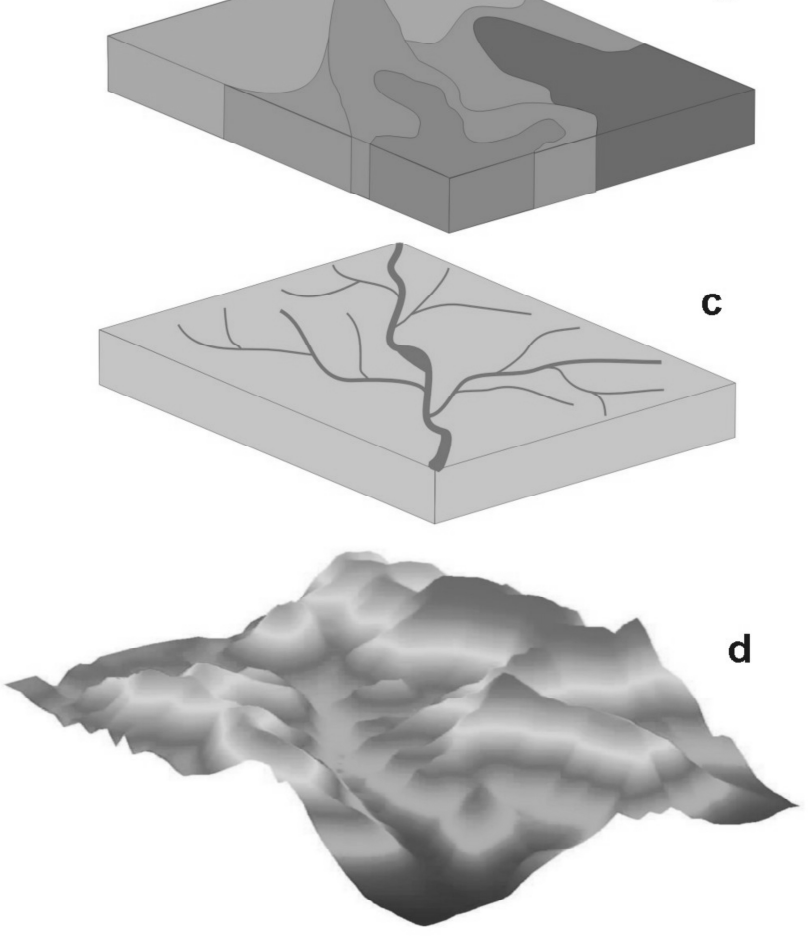

Rys.1. Cyfrowe warstwy tematyczne wykorzystywane w toku obliczeń modelu WISTOO: a) zagospodarowanie przestrzenne terenu, b) rozmieszczenie gleb, c) sieć hydrograficzna, d) numeryczny model terenu NMT

Fig.1. Digital thematic layers used in the calculations of the model WISTOO: a) spatial land use, b) distribution of soil, c) hydrographical network, d) digital terrain model DTM

Program estymacji przetwarza układ przestrzenny (x, y) na wektorowy. Ma to na celu optymalizację czasu obliczeniowego, aby program w trakcie wykonywania operacji dokładnie znał kolejność przetwarzania rastrów. Wektor obliczeniowy opracowany jest na podstawie hierarchii zasilania poszczególnych rastrów w procesie spływu powierzchniowego. Pierwszymi elementami są rastry, które rozpoczynają spływ powierzchniowy a ostatnim raster w przekroju zamykającym zlewnię (rys. 2). 


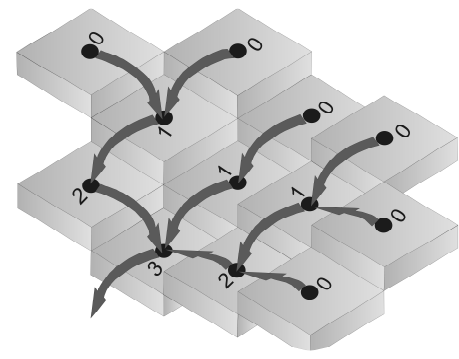

Rys. 2. Schemat wymiany wody pomiędzy rastrami w układzie quasidwuwymiarowym stosowany w modelu WISTOO

Fig. 2. Water exchange scheme between rasters in quasi two-dimensional system applied in the model WISTOO

\subsection{Transformacja opadu w odpływ - model właściwy}

Procedura transformacji opadu w odpływ umożliwia śledzenie hydrogramów przepływu w dwudziestu pięciu dowolnie wybranych przekrojach. $\mathrm{Na}$ rysunku 3 przedstawiono uproszczony schemat ideowy modelu WISTOO.

W przedstawionym schemacie opad efektywny wyznaczany jest na podstawie zdolności infiltracyjnej gruntu, czyli przekroczenia potencjalnych możliwości wsiąkania i przesiąkania przez powierzchnię gruntu natężenia opadu netto. Dodatkowo w modelu WISTOO uwzględniono spływ podpowierzchniowy, który odbywa się w strefie gleby. Proces ten bierze czynny udział w formułowaniu się wezbrań.

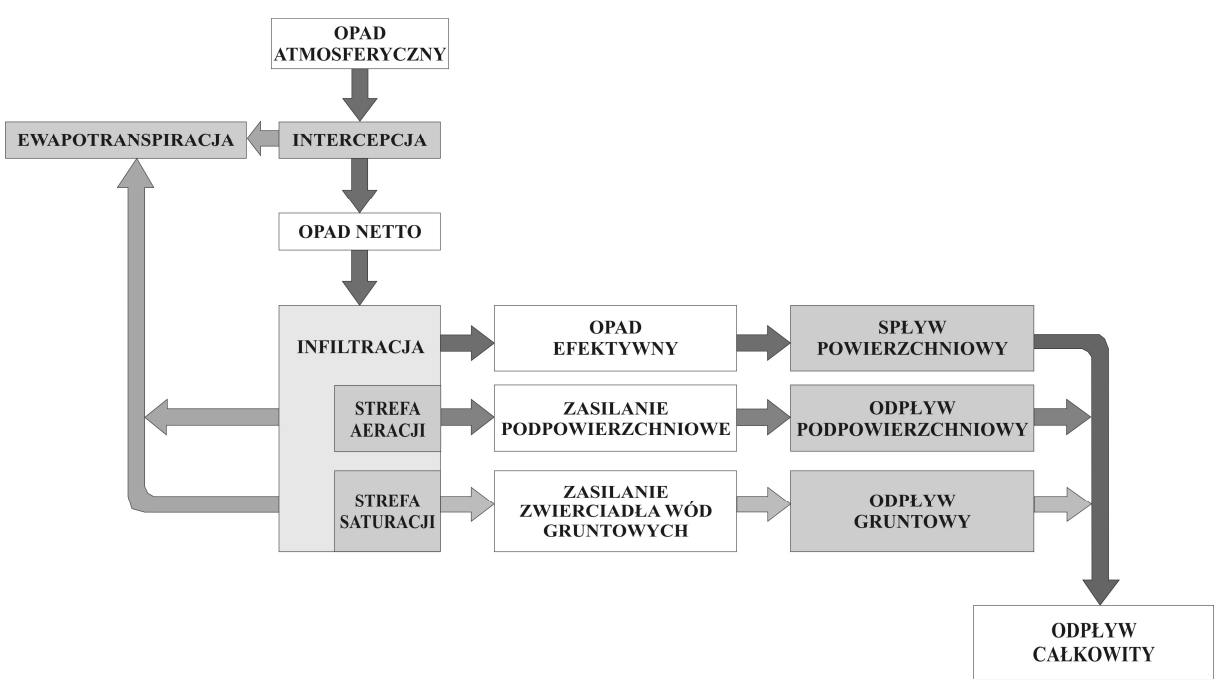

Rys. 3. Uproszczony schemat algorytmu obliczeniowego dla modelu transformacji opadu w odpływ

Fig. 3. Simplified scheme of the calculation algorithm for the model of rainfall-runoff transformation 


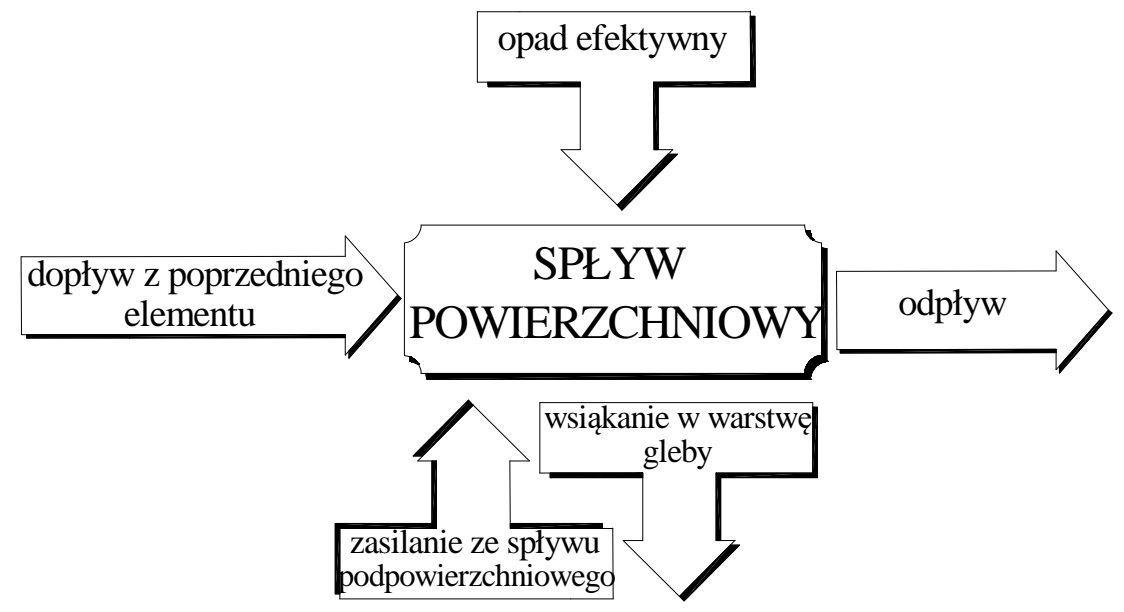

Rys. 4. Schemat obliczeniowy spływu powierzchniowego

Fig. 4. Calculation scheme of the surface flow

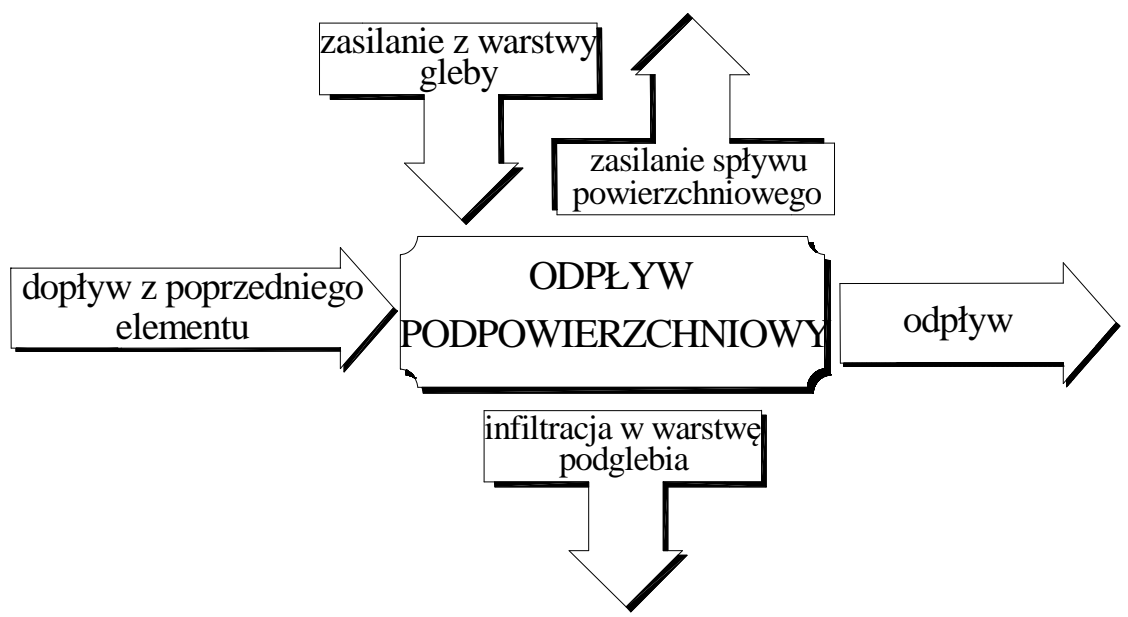

Rys. 5. Schemat obliczeniowy odpływu podpowierzchniowego

Fig. 5. Calculation scheme of the subsurface flow

Na rysunkach 4 i 5 przedstawiono wzajemną wymianę wody, jaką przewidziano w strukturze modelu pomiędzy spływem powierzchniowym i podpowierzchniowym. To odmienne podejście do opisu transformacji na obszarze zlewni skutkuje znacznie lepszym dopasowaniem do wezbrań rzeczywistych w wyznaczonych przekrojach. Tego typu rozwiązanie możliwe jest dzięki dwuwarstwowemu podziału gruntu na glebę i podglebie. 


\section{Usługi sieciowe OGC}

Kluczowym elementem niezbędnym do uruchomienia każdego model hydrologicznego są dane. W klasycznym modelu hydrologicznym dane pobierane są z komputera, na którym działa model, lub w bardziej zaawansowanych rozwiązaniach bezpośrednio $\mathrm{z}$ baz danych. W ostatnich latach niezwykłą popularność zyskała technologia usług sieciowych Open Geospatial Consortium (OGC) $[8,10]$, która prezentuje alternatywny sposób dystrybucji danych. Cechą wspólną usług sieciowych OGC jest praca w technologii klient-serwer oraz komunikacja $\mathrm{z}$ wykorzystaniem zestandaryzowanych protokołów. Przy pomocy usługi sieciowej pobierane są dane jedynie dla ściśle określonego obszaru. Dzięki standaryzacji, stosunkowo łatwe jest tworzenie aplikacji klienckich, które mogą pobierać dane przestrzenne z serwerów. Usługi sieciowe wykorzystywane są praktycznie przez wszystkie serwery mapowe (np. Google Maps) oraz aplikacje desktopowe (np. QGIS). Dostęp do usług sieciowych jest możliwy również z poziomu terminala lub przeglądarki internetowej, bez udziału żadnego dodatkowego programu.

Usługa pobierania danych przestrzennych Web Coverage Service (WCS) umożliwia pobieranie przez aplikację kliencką warstwy rastrowej z serwera. Na polskim centralnym serwerze Geoportal.gov.pl podane są adresy serwerów WCS udostępniających mapy: topograficzną, sozologiczną, hydrograficzną, hipsometryczną, ortofotomapę i cieniowanie.

Usługa pobierania danych przestrzennych Web Feature Service (WFS) zwraca obiekty geometryczne wraz z ich atrybutami, najczęściej w postaci wektorowej. Na Geoportalu [16] podane są adresy serwerów WFS udostępniających 17 warstw tematycznych.

Niestety jak podano na Geoportalu ,usługi pobierania WCS podobnie jak usługi pobierania WFS są zabezpieczone tzn. dostęp do zbioru źródłowego mają wyłącznie autoryzowani użytkownicy”. Na dzień dzisiejszy można więc uznać, że jedyną praktycznie funkcjonująca w Polsce usługą sieciową o dostępnie publicznym jest usługa przeglądania - Web Map Service (WMS) [9]. Udostępnia ona kompozycje mapowe w postaci obrazów bitmapowych. Jest to więc znakomite narzędzie dla potrzeb wizualizacji, ale niestety nie do analiz przestrzennych. Pozyskane obrazy bitmapowe mogą zostać zapisane lokalnie, ale pozyskane informacje opisane są w przestrzeni barw RGB, co utrudnia ich bezpośrednie wykorzystanie. Dodatkowym ograniczeniem jest maksymalny rozmiar pobieranego obrazu, definiowany w konfiguracji serwera dane usługi.

\section{Wykorzystanie usług sieciowych OGC przez model WISTOO}

W ramach prac nad reaktywacją modelu WISTOO i dostosowaniem go do współczesnych źródeł danych zostały przygotowane i przetestowane narzędzia służące do półautomatycznego pobierania danych z serwerów WMS oraz konwersji tak pozyskanych danych do formatu warstw rastrowych. Pierwsze próby są bardzo obiecujące, choć standard WMS jest najmniej nadający się do takich ce- 
lów w porównaniu z takimi formatami jak WFS czy WCS. Opracowane metody wykorzystania danych WMS, pozyskiwanych w sposób dynamiczny przez model WISTOO, dają gwarancje łatwego i skutecznego zintegrowania pozostałych, prostszych formatów przestrzennych.

Dotychczas dla potrzeb modelu WISTOO opracowano następujące metody:

- pozyskiwania danych dla większych obszarów poprzez ich podział na mniejsze fragmenty (tzw. kafle),

- konwersji 3-kanałowych bitmapowych obrazów RGB na indeksowane warstwy rastrowe $\mathrm{z}$ georeferencją,

- scalania kafli w jednolitą warstwę rastrową,

- przenoszenia kategorii tematycznych z referencyjnych warstw rastrowych na pobraną warstwę rastrową,

- wyznaczania statystyk dla zadanych obszarów (np. zlewni) na podstawie danych pochodzących z warstw rastrowych.

Na obecnym etapie prac, jako źródło informacji o pokryciu terenu wykorzystywane są dane $\mathrm{z}$ projektu CORINE Land Cover (CLC) [http://land.copernicus.eu/pan-european/corine-land-cover]. Są to dane aktualizowane dla całej Europy w cyklach kilkuletnich i udostępniane z rozdzielczością przestrzenną $100 \mathrm{~m}$. Ostatnie dane pochodzą z roku 2012.

Dotychczasowe dane o glebach pozyskiwane były $\mathrm{z}$ map gleboworolniczych. Alternatywnym źródłem danych glebowych może być European Soil Database v2.0 udostępniana w ramach europejskiego projektu Eurosoils [http://eusoils.jrc.ec.europa.eu/]. Rastrowe dane o glebach mają rozdzielczość przestrzenną $1 \mathrm{~km}$ i podobnie jak CLC obejmują swoim zasięgiem całą Europę.

Niezaprzeczalną zaletą wykorzystania europejskich baz danych jest możliwość zaimplementowania modelu WISTOO w dowolnej zlewni na obszarze Europy. Pozostałe dane o charakterze topograficznym (NMT i hydrografia) są również możliwe do pozyskiwania w sposób zautomatyzowany.

Połączenie zautomatyzowanego pre-processingu danych mapowych dla celów kalibracji modelu WISTOO z danymi meteorologicznymi pozyskiwanymi np. z serwisu OGIMET stwarza całkiem nowe perspektywy wykorzystania modeli tego typu.

\section{Podsumowanie i wnioski}

Tempo rozwoju modelu WISTOO oraz liczba jego wdrożeń zdeterminowane są funkcjonalnością modelu rozumianą jako łatwość jego implementacji w dowolnej zlewni. Dotychczasowe podejście polegające na każdorazowym przygotowywaniu podkładów mapowych znacząco ograniczało liczbę potencjalnych użytkowników. Wraz z wdrożeniem rozwiązań automatyzujących proces wstępnego przygotowania danych z wykorzystaniem usług sieciowych OGC, implementacja modelu stanie się możliwa również dla osób nie zaznajomionych z zagadnieniami systemów informacji przestrzennej. 
Jako zalety takiego rozwiązania należy wymienić:

- skrócenie czasu poświęconego na przygotowanie danych (pre-processing),

- ułatwienie pracy z modelem hydrologicznym dla osób nie znających narzędzi GIS,

- możliwość wykorzystania najbardziej aktualnych danych.

Potencjalnymi zagrożeniami rozwoju modelu WISTOO w kierunku usług sieciowych jest restrykcyjna polityka udostępniania danych w Polsce oraz nie zawsze dostosowana infrastruktura informatyczna (przepływność łączy, wydajność serwerów usług OGC). Prace nad wykorzystaniem usług WFS oraz WCS jako źródeł danych do modelu WISTOO rozpoczną się, gdy zostaną publicznie udostępnione w Polsce dane w tych standardach. Innowacyjne rozwiązania wymagają nie tylko nowoczesnych rozwiązań technicznych, lecz również otwartości w obszarze udostępniania informacji.

Praca zostata wykonana $w$ ramach projektu S-1/229/2015/DS „Wptyw czynników antropogenicznych na ilościowe i jakościowe wtaściwości procesów hydrologicznych wzlewni”; Zadanie 2 „Identyfikacja i estymacja parametrów matematycznych modeli podstawowych procesów hydrologicznych".

\section{Literatura}

[1] Eastman J.R.: IDRISI32 Release2, Guide to GIS and Image Processing. Clark University. Vol. 2, 2001 Worcester.

[2] Gądek W., Banach Wł., Bodziony M., Książyński W., Łabuda P., Szczepanek R., Szypułka P.: Integral distributed rainfall-runoff model, Materiały konferencyjne "Las i woda" 1998 s. 142-148.

[3] Gądek W., Książyński K., Nachlik E., Szczepanek R., Ozga-Zielińsk M.: Matematyczny model transformacji opadu w odpływ WISTOO. Monografia Komitetu Gospodarki Wodnej PAN „Wizualizacja Integralnego Systemu Transformacji Opadu w Odpływ [WISTOO] - podstawy i aplikacje w ocenie zagrożenia powodziowego" z. 182001 s. 9-69.

[4] Gądek W.: Matematyczny model odpływu ze zlewni z zastosowaniem zdekomponowanej przestrzennie siatki obliczeniowej. Zeszyty Naukowe Politechniki Krakowskiej 492002 ss. 134.

[5] Gądek W., Nachlik E.: Komputerowy model opad-odpływ dla zlewni Bystrzycy Dusznickiej. Materiały konferencyjne „Problemy hydrotechniki: Współczesne podstawy planowania i projektowania w inżynierii i gospodarce wodnej”. 2003 s. 353-368.

[6] Gądek W., Banach Wł.; Fiołka I.: Zastosowanie modelu geomorfologicznego do wyznaczania wezbrań hipotetycznych w zlewniach niekontrolowanych, 2012 s. 5967.

[7] Gnouma R. Aide à la calibration d'un modèle hydrologique distribué au moyen d'une analyse des processus hydrologiques : application au bassin versant de l'Yzeron. http://theses.insa-lyon.fr/publication/2006ISAL008. 2006.

[8] Kubik, T.: GIS - rozwiązania sieciowe, 2009, PWN, Warszawa.

[9] Kubik, T., Iwaniak, A. (2007). Technologie interoperacyjne w projekcie geoportal na przykładzie użycia usługi WMS. Roczniki Geomatyki, 5, s. 71-83. 
[10] Michalak, J. "Inicjatywa OWS-5-kolejny etap rozwoju i harmonizacji specyfikacji OGC dotyczących geoprzestrzennych usług sieciowych." Roczniki Geomatyki 6 (2008): 65-74.

[11] Osuch B., Gądek W., Homa A., Cebulska M., Szczepanek R., Hebda-Małocha A. Methods of estimating the elements of water balance in a forested catchment basin. Journal of Water and Land Development. 2009 s. 19-40.

[12] Ozga-Zielińska M., Gądek W., Książyński K., Nachlik E., Szczepanek R.: Mathematical model of rainfall-runoff transformation - WISTOO. Mathemalical Models of Large Watershed Hydrology, Ed. Singh V. P., Frevert D.K. Water Resources Publications, LLC, Littleton, Colorado 2002, s. 811-860.

[13] Pietrusiewicz I., Cupak A., Wałęga A., Michalec B. The use of NRCS synthetic unit hydrograph and Wackermann conceptual model in the simulation of a flood wave in an uncontrolled catchment. Journal of Water and Land Development. No. 232014 s. 53-59.

[14] Szczepanek R., Gądek W. GIS-based mathematical model of rainfall-runoff transformation for mountain environment. Conference on Geographic Information Systems and Remote Sensing in Mountain Environment Studies EnviroMount 2002.

[15] Wałęga A.: Application of HEC-HMS programme for the reconstruction of a flood event in an uncontrolled basin. Journal of Water and Land Development. No 18 2013 s. $13-20$.

[16] Geoportal, http://geoportal.gov.pl [dostęp: 1 maja 2015].

\section{HYDROLOGICAL MODEL WISTOO - REACTIVATION}

\section{S u m m a r y}

Model of rainfall - runoff transformation WISTOO was developed in 1996 in the Division of Hydrology in the Institute of Water Engineering and Water Management at the Cracow University of Technology in cooperation with the Warsaw University of Technology. It was made on the order of Ministry of Environment Protection, Natural Resources and Forestry, financed by the funds from the National Fund for Environmental Protection and Water Management. Model WISTOO i.e. Visualisation of Integral Rainfall-Runoff Transformation System is the only model in the country defined as the integral model with distributed parameters, that may be used for the catchments from 10 to $1000 \mathrm{~km}^{2}$. The parameters for the model are determined based on four thematic layers: DTM (Digital Terrain Model), hydrographical network, land cover category and soil category. The thematic layers are processed into IDRISI format. The demand for hydrological calculations conducted while using the hydrological models with distributed parameters has increased recently, but the most significant limitation is still preparation of the current thematic layers. To meet this demand, the work on exploiting the data coming from the web services (WMS, WFS, WCS) in the model WISTOO has been started. In the article there are discussed the advantages and disadvantages of such solution.

Keywords: surface flow, subsurface flow, hydrological processes, WMS, WFS, WCS

Przestano do redakcji:30.05.2015 $r$.

Przyjęto do druku:30.10.2015 r.

DOI: $10.7862 / r b .2015 .99$ 